predictors of TAS-20 values were to be fibromyalgic and to have mild-to-severe depression according to BDI. In multiple logistic regression, alexithymia was significantly associated to $\mathrm{BDI}$ score (OR $1.2,95 \% \mathrm{Cl} 1.0-1.4)$ and inversely associated to cognitive impairment (OR $0.1,95 \% \mathrm{Cl} 0.02-0.8$ ).

Conclusions: SLE patients frequently present alexithymic tract. Alexithymia seems to be associated neither to disease feature, to disease course (activity and damage) and to SLE therapy, nor to HR-QoL expressed by SF-36. Nevertheless, alexithymia could be tightly related to QoL-associated factors as depression and fibromyalgia

Disclosure of Interest: None declared

DOI: 10.1136/annrheumdis-2017-eular.6679

\section{SAT0274 URINARY VITAMIN D-BINDING PROTEIN AS A BIOMARKER FOR LUPUS NEPHRITIS}

D.J. Go ${ }^{1,2}$, J.Y. Lee ${ }^{2}$, M.J. Kang ${ }^{2}$, I.A. Choi ${ }^{3}$, E.Y. Lee ${ }^{1}$, E.B. Lee ${ }^{1}$, E. Yi ${ }^{2}$, Y.W. Song ${ }^{1,2}$. 'Department of Internal Medicine, Seoul National University' Hospital; ${ }^{2}$ Department of Molecular Medicine and Biopharmaceutical Sciences, Graduate School of Convergence Science and Technology, and College of Medicine, Medical Research Institute, Seoul National University, Seoul; ${ }^{3}$ Department of Internal Medicine, Chungbuk National University Hospital, Cheongju, Korea, Republic Of

Background: Lupus nephritis (LN) is a major complication of systemic lupus erythematosus (SLE). However, conventional biomarkers for assessing renal disease activity are imperfect in predicting clinical outcomes associated with LN.

Objectives: The aim of this study is to identify urinary protein biomarkers that reliably reflect the disease activity or predict clinical outcomes.

Methods: A quantitative proteomic analysis, using liquid chromatography coupled with tandem mass spectrometry (LC-MS/MS), was performed to identify protein biomarker candidates that can differentiate between SLE patients with and without $\mathrm{LN}$. Selected biomarker candidates were further verified using urine samples from a larger cohort of SLE patients ( $n=121)$ by enzyme-linked immunosorbent assay (ELISA) to investigate their predictive values for $L N$ activity measure. Furthermore, association between urinary level of selected panel of potential biomarkers and prognosis of LN was assessed with a 4-year follow-up study of renal outcomes. Results: From proteomic assay, vitamin D binding protein (VDBP), transthyretin (TTR), retinol binding protein 4 (RBP4) and prostaglandin D synthase (PTGDS) were selected as candidates for quantification. These proteins were significantly elevated in SLE patients with LN, especially in patients with active LN $(n=21)$. Among them, VDBP well correlated with severity of proteinuria (rho $=0.661$, $P<0.001$ ) and renal SLE disease activity index (renal SLEDAI) ( $r$ ho $=0.520$, $\mathrm{P}<0.001$ ). In the 4 -year follow-up, VDBP was a significant risk factor (hazard ratio $9.627,95 \% \mathrm{Cl} 1.698$ to $54.571, \mathrm{P}=0.011$ ) for the development of proteinuric flare (randum urine protein/creatinine ratio $>1.0$ ) in SLE patients without proteinuria (random urine protein/creatinine ratio $<0.5)(n=100)$ after adjustments of multiple confounders.

Conclusions: Urinary VDBP correlated with proteinuria and renal SLEDAI, and predicted the development of proteinuria.

Disclosure of Interest: None declared

DOI: 10.1136/annrheumdis-2017-eular.4356

\section{SAT0275 COMPARISON OF CLINICAL AND SEROLOGICAL DIFFERENCES ACCORDING TO THE AUTOANTIBODY CLUSTER IN WOMEN WITH SYSTEMIC LUPUS ERYTHEMATOSUS: RESULTS FROM THE KOREAN LUPUS NETWORK (KORNET) REGISTRY}

\section{D.-J. Park, J.-H. Kang, J.-E. Kim, K.-E. Lee, S.-S. Lee. Chonnam National} University Medical School and Hospital, Gwangju, Korea, Republic Of

Objectives: Individual autoantibodies are associated with the clinical features in patients with systemic lupus erythematosus (SLE). However, few studies have investigated differences in disease presentation based on autoantibody profiles in Asian patients with SLE. This study evaluated autoantibody clusters and compared the clinical and serological presentation and clinical outcome in Korean SLE patients.

Methods: The Korean Lupus Network (KORNET) is a nationwide multicenter, hospital-based registry, set up to prospectively assess outcomes in Korean SLE patients. Of the 505 SLE patients enrolled in the KORNET registry from July 2014 to November 2015, the study group comprised 339 consecutive female SLE patients. Seven autoantibodies (anti-dsDNA, anti-Sm, anti-RNP, anti-Ro, anti-La, lupus anticoagulant (LAC), and anti-cardiolipin antibody [aCL]) were selected for cluster analysis using the K-means cluster analysis procedure.

Results: Three distinct autoantibody clusters were identified: cluster 1, antidsDNA and anti-Ro; cluster 2, anti-RNP; and cluster 3, anti-RNP, anti-Ro, and anti-La. Compared with patients in clusters $2(n=99)$ and $3(n=85)$, patients in cluster $1 \quad(n=155)$ had a shorter symptom duration before SLE diagnosis and higher incidence of biopsy-proven lupus nephritis. Patients in cluster 3 had a higher incidence of discoid rash, central nervous system involvement, lupus pancreatitis, pulmonary arterial hypertension, Raynaud's phenomenon, and premature gonadal failure. In addition, patients in cluster 3 had the lowest proportion of mean prednisolone $>7.5 \mathrm{mg} /$ day in the medication history.
Conclusions: Autoantibody clusters were associated with the clinical features in women with SLE. Clustering autoantibodies could be a valuable approach for differentiating between various clinical subsets of SLE, and may help to guide prediction of the subsequent clinical course and organ damage in these patients. Disclosure of Interest: None declared

DOI: 10.1136/annrheumdis-2017-eular.2361

\section{SAT0276 EYE TOXICITY IN PATIENTS WITH SYSTEMIC LUPUS ERITHEMATOSUS TREATED WITH ANTIMALARICS IN DOMINICAN REPUBLIC}

E. Rodríguez-Bautista ${ }^{1}$, Y. Cruz-Rojas ${ }^{1}$, I. Mercedes-Núñez ${ }^{1}$,

E. Tejada-Reyes ${ }^{1}$, N. Abreu-Arbaje ${ }^{2}$, M. Arbaje-Khoury ${ }^{2}$, V. Rosario ${ }^{1}$

R. Munoz-Louis ${ }^{1}$, R. Peña-Blanco ${ }^{3}$, T. Valdez-Lorie ${ }^{3}$, R. Alba-Fériz ${ }^{1}$.

${ }^{1}$ Rheumatology, Hospital Docente Padre Billini; ${ }^{2}$ Ophthalmology, Centro de

Oftalmología y Glaucoma; ${ }^{3}$ Rheumatology, Hospital Docente Universitario

Francisco Moscoso Puello, Santo Domingo, Dominican Republic

Background: Antimalarics are derivatives of quinine indicated in the treatment of autoimmune inflammatory diseases. The mechanism of antimalarial toxicity is unclear. It is hypothesized that toxicity is a result of drug binding to retinal pigmentary epithelium, damaging photoreceptors resulting in vision loss. Early retinal toxicity is asymptomatic with subtle alterations in foveal pigmentation generally not evident at routine ophthalmologic examination, progressively producing classic "bull's-eye" maculopathy, manifested as a decrease in central, color and night vision, and central scotoma. To prevent the sequelae of antimalarial use, sensitive tools are used to detect toxic maculopathy such as: campimetry, optical coherence tomography (OCT) and eye fundus.

Objectives: To evaluate ocular toxicity in patients with systemic lupus erythematosus treated with antimalarics.

Methods: Multicenter cross-sectional study, two rheumatology departments clinical records were analyzed from January 2016 to January 2017, with diagnosis of systemic lupus erythematosus according to ACR 1997 criteria, with $\geq 4$ years using antimalarial drugs. 298 patients were identified, 93 of them fulfilled inclusion criteria, and were evaluated by two retinologists performing OCT on each patient. Accumulated antimalarial doses were calculated and all variables were analyzed with SPSS software V.22.

Results: $97.8 \%$ were females, the mean age was $37.4 \pm 13$ years, $78.5 \%$ of the patients used $4 \mathrm{mg} / \mathrm{kg}$ of chloroquine (CQ) versus $21.5 \%$ took $6 \mathrm{mg} / \mathrm{kg}$ of hydroxychloroquine (HCQ), the mean use duration was $5.1 \pm 2$ years, $19.4 \%$ of patients had retinal pigment epithelium (RPE) changes suggesting maculopathy, of which, $15 \%$ used $C Q$ versus $4.35 \%$ with $\mathrm{HCQ}, 54.50 \%$ using $\mathrm{CQ}$ had a cumulative dose of 365 grams, $10.75 \%$ with HCQ had cumulative doses of 292 grams, and the mean for the cumulative dose of both antimalarials was 485 grams.

Conclusions: Previous studies have shown that the antimalarial toxicity rate are between $7.5 \%>13.1 \%$, in our population we observed that our patients had a higher toxicity rate associated with the use of $C Q$ compared to $H C Q$, and no association was found relevant with other variables. We understand that both, patients and physicians who manage this drug, should be educated about the need to maintain an adequate ophthalmologic control, due to the progression of retinopathy from 1 to 3 years after discontinuation of treatment. It is necessary to carry out prospective studies with a greater number of patients.

References:

[1] Block, J.A. (1998) Hydroxychloroquine and retinal safety. The Lancet 351(9105), 771-771.

[2] Battagliotti, C., Gentiletti, A., Pons-Estel, B. Lupus Eritematoso Sistémico, Aspectos Clínicos y Terapéuticos. $1^{\circ}$. Edición, 42, 515-531.

[3] Rosenbaum, J.T., Mount, G.R., et al. (2016). Avoiding Antimalarial Toxicity.Arthritis \& Rheumatology.

[4] Marmor MF, Melles RB. Hydroxychloroquine and the retina. JAMA 2015;313:847-8.

Disclosure of Interest: None declared

DOI: 10.1136/annrheumdis-2017-eular.4142

\section{SAT0277 COGNITIVE DYSFUNCTION IN PATIENTS WITH SYSTEMIC LUPUS ERYTHEMATOSUS IN DOMINICAN REPUBLIC}

E. Tejada-Reyes ${ }^{1}{ }^{\text {I. I. Mercedes-Nuñez }}{ }^{1}$, Y. Cruz-Rojas ${ }^{1}$,

E. Rodríguez-Bautista ${ }^{1}, \mathrm{~K}$. Polanco-Soriano ${ }^{2}$, M. Perdomo-Ramirez ${ }^{2}$,

V. Rosario ${ }^{1}$, R. Muñoz-Louis ${ }^{1}$, R. Peña-Blanco ${ }^{3}$, T. Valdez-Lorie ${ }^{3}$,

R. Alba-Fériz ${ }^{1} .{ }^{1}$ Rheumatology; ${ }^{2}$ Psychology, Hospital Docente Padre Billini;

${ }^{3}$ Rheumatology, Hospital Docente Universitario Dr. Francisco E. Moscoso Puello, Santo Domingo, Dominican Republic

Background: Cognitive dysfunction (CD) is a deficit of cognitive faculties including attention, memory, language, executive function and visuospatial processing. CD is the most frequent neuropsychiatric manifestation of SLE (55-80\%) 1 and this is 3 times higher in patients with Systemic Lupus Erythematosus (SLE) than in healthy subjects.2 This is not routinely evaluated because it requires a lot of time. Brief and simple questionnaires are needed to identify $C D$.

A study carried out by D'Amico et al. evaluated 21 SLE patients and all of them had CD.3 Pedraza et al. analyzed the MMSE score and Montreal Cognitive 